\title{
Elephant Foot Yam (Amorphophallus paeoniifolius): Osmotic Dehydration and Modelling
}

\author{
Sangeeta* and Bahadur Singh Hathan
}

Department of Food Engineering and Technology, Sant Longowal Institute of Engineering and Technology, (SLIET), Sangrur, Punjab, India

\begin{abstract}
Osmotic dehydration of elephant foot yam was done in different concentration of sucrose solution at different temperature for regular interval of time. The osmotic solution concentrations used were $40,50,60^{\circ} \mathrm{Bx}$, osmotic solution temperatures were 35 , $45,55^{\circ} \mathrm{C}$ and the process duration varied from 0 to $240 \mathrm{~min}$. The fruit to solution ratio was kept constant i.e. $1: 5$ (w/w) during all the experiments. The experimental data of water loss and solute gain was fitted to different empirical kinetic models viz. Peleg, Penetration, Magee, and Azuara to know the best fitted model to the experimental data. Out of all the applied models, Magee model and Azuara model were the best fitted as compared to other models for water loss and solute gain of elephant foot yam, respectively.
\end{abstract}

Keywords: Elephant foot yam; Osmotic dehydration; Kinetics; Empirical models

\section{Introduction}

Elephant foot yam, Amorphophallus paeoniifolius is very much prevalent in Philippines, India, Malaysia, Indonesia, China, Sri Lanka and many other Southeast Asian countries [1]. The tubers of elephant foot yam are commonly used as a vegetable after cooking and in preparation of indigenous ayurvedic medicines [2]. The tubers are cheapest source of carbohydrates mainly starch and fibres, vitamins and minerals [3] and play a importantl role in food security and are the important staple or subsidiary food for a large group of population [4]. Tubers have a short shelf life because of their high moisture content. One of the best ways to preserve them may be by processing methods like drying, dehydration or by obtaining flour and/or starches. Due to the reduction of moisture content by various means the shelf life of corms can be increased. In recent years, for preservation of fruits and vegetables osmotic dehydration technique is gaining considerable amount of attention due to its potential to keep sensory and nutritional properties similar to the fresh fruits [5]. Osmotic dehydration is the process of water removal by immersion of water containing cellular solid in a concentrated aqueous solution of high osmotic pressure (hypertonic media) for a specified time and temperature. Water removal in osmotic dehydration is based on the natural and non-destructive phenomenon of osmosis across cell membranes. The driving force for water removal from cell is potential difference between osmotic pressure of fresh material and surrounding solution [6]. Osmotic dehydration is actually combination of simultaneous water and solute diffusion process [7] means mass transfer consists of two major simultaneous countercurrent fluxes of water and solutes because complex cell wall structure is not perfectly selective [8]. Leaching of negligible amount of natural solutes from food into solution has considered as third minor flux [9]. This pre-treatment minimize color losses as well as reduce nutrient losses due to drying. The influence of the main process variables such as concentration and composition of osmotic solution, temperature, immersion time, pre-treatments, agitation, nature of food and its geometry, solution to sample ratio on the kinetics of mass transfer and product quality have been studied extensively $[10,11]$. Considerable effort has been made toward developing models to predict the mass transfer kinetics of osmotic dehydration process. In this regard, several equations based on Fick's second law have been proposed which are not useful practically because of unrealistic assumptions and complexity of the some equations. Some researchers like Peleg [12], Azuara
[13], Magee et al. [14] and Rahman [15] etc. recommended simpler empirical equations including parameters with physical meaning. These empirical equations have been used to model the rate of dehydration of different plant-based materials [16-21]. However, literature about the suitability of these equations to model the mass transfer kinetics of osmotically dehydrated elephant foot yam is very rare. So, the aim of present study was to evaluate the effect of temperature and sucrose solution concentration on mass transfer during osmotic dehydration process and to assess the predictive capacity of Peleg, Azuara, Magee and Rahman equations during osmotic dehydration of elephant foot yam cubes in sucrose solution.

\section{Material and method}

\section{Osmotic dehydration of elephant foot yam cubes}

Osmotic dehydration elephant foot yam (EFY) cubes having size $1 \mathrm{~cm} \times 1 \mathrm{~cm} \times 1 \mathrm{~cm}$ was done in osmotic solution of sucrose having different concentrations $\left(40,50,60^{\circ} \mathrm{Bx}\right)$ and solution temperature $(35$, $45,55^{\circ} \mathrm{C}$ ). Vegetable to solution ratio was kept 1:5 (w/w) [22] during osmotic dehydration for a regular interval of time period of $(0-240$ min). The temperature of the osmotic solution was maintained by hot water bath agitating@50 oscillations per minute. Agitation was given during osmosis for reducing the mass transfer resistance at the surface of the fruit and for good mixing and close temperature control in osmotic medium [23]. Stain less steel containers (of approximately $150 \mathrm{ml}$ capacity) containing osmotic solution were kept in hot water bath. After attainment of desired temperature of the solution, known weight of EFY cubes was put in to the container. The EFY cubes from each container were removed at specified time and were immediately rinsed with running water to remove the solute adhered to fruit surface.

*Corresonding author: Sangeeta, Department of Food Engineering and Technology, Sant Longowal Institute of Engineering and Technology, (SLIET), Sangrur, Punjab, India, Tel: 09463216875; Fax: 28480059; E-mail: ssaini.kataria@gmail.com

Received August 17, 2015; Accepted September 02, 2015; Published September 09,2015

Citation: Sangeeta, Hathan BS (2015) Elephant Foot Yam (Amorphophallus paeoniifolius): Osmotic Dehydration and Modelling. J Food Process Technol 6 499. doi:10.4172/2157-7110.1000499

Copyright: ( 2015 Sangeeta, et al. This is an open-access article distributed unde the terms of the Creative Commons Attribution License, which permits unrestricted use, distribution, and reproduction in any medium, provided the original author and source are credited. 
The cubes were then spread on muslin cloth to remove the free water from the outer surface of the EFY cubes. The cubes were then put in the pre-weighed petri-dish for determination of dry matter by oven method. During experimentation, it was assumed that the amount of solid (sugars, acids, minerals, vitamins) leaching out of product into the medium was considered quantitatively negligible [24]. The water loss and solute gain were calculated as given below:

\section{Let, initial dry matter of fresh vegetable $=\mathrm{Z} \%$}

Initial weight of vegetable taken for osmotic dehydration $=\mathrm{W}_{0}(\mathrm{~g})$

$\therefore$ Initial dry matter of vegetable $=\frac{W_{o} \times Z}{100}=\mathrm{S}_{\mathrm{o}}$ (say)

Let the weight of vegetable after osmotic dehydration for any time $\mathrm{t}=\mathrm{W}_{\mathrm{t}}(\mathrm{g})$

And the dry matter of vegetable after osmotic dehydration for time $\mathrm{t}=\mathrm{S}_{\mathrm{t}}(\mathrm{g})$

Then, Weight reduction, $\mathrm{WR}=\mathrm{W}_{\mathrm{o}}-\mathrm{W}_{\mathrm{t}}(\mathrm{g})$

Solute gain after osmotic dehydration for time $t, S G=S_{t}-S_{o}(g)$

Water Loss, $\mathrm{WL}=\mathrm{WR}+\mathrm{SG}$

Water loss in $\mathrm{g} / 100 \mathrm{~g}$ fresh sample $=\frac{W L}{W_{o}} \times 100$

Solute gain in $\mathrm{g} / 100 \mathrm{~g}$ fresh sample $=\frac{S G}{W_{o}} \times 100$

Validation of empirical models for osmotic dehydration of EFY cubes

The validity of empirical models for water loss and solute gain during osmotic dehydration (Table 1) was checked by non linear regression technique. Azuara et al. [13] developed a model from mass balance considerations to predict the kinetics and final equilibrium point of osmotic dehydration by using data obtained during relatively short period of osmosis. In Azuara model, the constant $\beta$ is related to the rates of water diffusion out from the sample $\left(\mathrm{min}^{-1}\right)$. For solute gain instead of $\beta_{1}$ and $W L_{\infty}$, constant used are $\beta_{2}$ and, otherwise the formula used is same as that of water loss.

\section{Adequacy of fit of empirical models}

To fit the experimental data to the various empirical models, regression analysis has been carried out by statistical software STATSTICA 7.0 for windows (Statsoft, Inc Tulsa OK U.SA.). To select the best equation various statistical parameters, such as reduced $\chi^{2}$ and root mean square error (RMSE) in addition to $R^{2}$, were also used as primary criterion [18]. For evaluating nonlinear mathematical models, these parameters are not a good criterion therefore, to select the best equation to account for variation in the drying curves of the dried samples, the percent mean relative deviation modulus $(E \%)$ that indicate the deviation of the observed data from the predicted line was also used as recommended by several authors in their drying studies [25]. Therefore, the best model was chosen as one with the highest coefficient of correlation $\left(R^{2}\right)$; and the least $\chi^{2}$, RMSE, and mean relative deviation modulus (E\%)

$\mathrm{R}^{2}$ is a measure of the amount of variation around the mean explained by model.

Chi Square $=\chi^{2}=\sum_{i=1}^{N}\left[\frac{(\text { Experimental } \text { Value }- \text { predicted value })^{2}}{(N-n)}\right]$ (3)

Where, $\mathrm{n}=$ no. of unknown and

\section{$\mathrm{N}=$ Data point measured}

$R M S E=$ Root mean square error $=\sum_{i=1}^{N}\left[\sqrt{\frac{(\text { Experimental value }- \text { predicted value })^{2}}{N}}\right]$

The mean relative deviation $E(\%)$ is an absolute value that was used because it gives a clear idea of the mean divergence of the estimated data from the measured data.

$$
E(\%)=\frac{100}{N} \sum_{i=1}^{N}\left|\frac{\text { Experimental Value }- \text { predicted value }}{\text { Experimental value }}\right|
$$

The values of $\mathrm{E}$ less than 5.0 indicate an excellent fit, while values greater than 10 are indicative of a poor fit.

\section{Results and Discussion}

During the experiments on osmotic dehydration of EFY cubes an increase in water loss and solute gain has been observed with increase of osmotic solution concentration, process temperature and time. The rates of water loss and solute gain were higher in the initial stages and approached to zero in the later stages. The process variables have significant effect on the constants and exponents of the various empirical models fitted to the water loss and solute gain data obtained during osmotic dehydration. The validation of various models for water loss and solute gain during osmotic dehydration of EFY cubes has been discussed below.

\section{Validation of Empirical Models for Water Loss}

The values of statistical parameters, models constants and coefficients for water loss during osmotic dehydration are given in Tables 2 and 3. Out of the fitted models, the values of $\chi^{2}$, RMSE and E\% were lower for Magee model in comparison to the Peleg model and Azuara model. There was a very good adequacy between predicted and observed data with correlation coefficient ' $\mathrm{R}^{2}$ ' higher than 0.96 for water loss in case of Magee model. However, Azarpazhooh and Ramaswamy [26] reported that Peleg model was a best fit model for water loss in osmotic dehydration, but this model did not fit to the experimental data in the present study because of high value of E\%, RMSE and $\chi^{2}$.

The Azuara model (Table 3 ) indicates that the predicted values of equilibrium water loss were $40.231,49.786,59.324 \mathrm{~g} / 100 \mathrm{~g}$ of sample at $35,45,55^{\circ} \mathrm{C}$, respectively, for osmotic solution of $50^{\circ} \mathrm{Bx}$ concentration. Therefore, with increase of temperature of osmotic solution, the values of water loss at equilibrium have been increased. The predicted values of equilibrium water loss were 57.14, 59.32, $60.24 \mathrm{~g} / 100 \mathrm{~g}$ of fresh fruit in $40,50,60^{\circ} \mathrm{Bx}$, respectively, at $55^{\circ} \mathrm{C}$ of osmotic solution temperature. Therefore, with increase of concentration of osmotic solution, the values of water loss at equilibrium have been increased. The values of $\beta_{1}$ indicates that the rates of water loss were higher at higher concentrations and temperature in comparison to the low values of concentration and temperature may be due to the fact that increase in osmotic solution concentration increases the concentration gradient

\begin{tabular}{|l|l|c|}
\hline Model Name & Model & Reference \\
\hline Penetration model & $\mathrm{WL}$ or $\mathrm{SG}=\mathrm{K} \times \sqrt{t}$ & {$[15]$} \\
\hline Peleg Model & $\mathrm{WL}$ or $\mathrm{SG}=\mathrm{K}_{1}+\mathrm{K}_{2} \times \mathrm{t}$ & {$[12]$} \\
\hline Magee Model & $\mathrm{WL}$ or $\mathrm{SG}=\mathrm{A}+\mathrm{K} \times \mathrm{t}^{1 / 2}$ & {$[14]$} \\
\hline Azuara Model & $W L_{t}$ or $S G_{t}=\frac{\beta_{1} t\left(W L_{\infty}\right)}{1+\beta_{1} t}=\frac{\left(W L_{\infty}\right) t}{\frac{1}{\beta_{1}}+t}$ & {$[13]$} \\
\hline
\end{tabular}

Table 1: Selected osmotic dehydration models. 
Citation: Sangeeta, Hathan BS (2015) Elephant Foot Yam (Amorphophallus paeoniifolius): Osmotic Dehydration and Modelling. J Food Process Technol 6: 499. doi:10.4172/2157-7110.1000499

Page 3 of 5

\begin{tabular}{|c|c|c|c|c|c|c|c|c|c|c|c|c|c|}
\hline \multirow[b]{2}{*}{ Conc $\left({ }^{\circ} \mathrm{Bx}\right)$} & \multirow[b]{2}{*}{ Temp. $\left({ }^{\circ} \mathrm{C}\right)$} & \multicolumn{6}{|c|}{ Magee model (water loss) } & \multicolumn{6}{|c|}{ Peleg model (water loss) } \\
\hline & & A & $\mathbf{K}$ & $\mathbf{R}^{2}$ & $\chi^{2}$ & $E \%$ & RMSE & $\mathrm{K}_{1}$ & $\mathrm{~K}_{2}$ & $\mathbf{R}^{2}$ & $\chi^{2}$ & $\mathrm{E} \%$ & RMSE \\
\hline 40 & 35 & 3.01677 & 2.5059 & 0.97 & 6.1022 & 11.1078 & 2.5723 & 14.78721 & 0.12359 & 0.91 & 16.9309 & 18.754 & 4.1147 \\
\hline 40 & 45 & 6.2810 & 6.3820 & 0.98 & 1.6144 & 4.5476 & 1.3710 & 17.78264 & 0.12849 & 0.92 & 6.84894 & 11.119 & 2.61704 \\
\hline 40 & 55 & 3.7845 & 3.8855 & 0.97 & 4.7640 & 6.4143 & 2.2828 & 20.80045 & 0.19062 & 0.90 & 22.1364 & 15.7564 & 4.70493 \\
\hline 50 & 35 & 2.0695 & 2.0795 & 0.99 & 1.3906 & 4.3637 & 1.2793 & 15.54508 & 0.15215 & 0.92 & 10.15608 & 13.80795 & 3.1868 \\
\hline 50 & 45 & 7.7284 & 7.7164 & 0.98 & 4.2946 & 6.6693 & 2.0825 & 21.47233 & 0.15069 & 0.88 & 16.8150 & 14.25272 & 4.10061 \\
\hline 50 & 55 & 4.9950 & 4.8960 & 0.98 & 3.1760 & 4.9317 & 1.7724 & 23.45795 & 0.21256 & 0.92 & 20.9119 & 13.5888 & 4.5729 \\
\hline 60 & 35 & 5.5333 & 5.4343 & 0.98 & 3.1847 & 5.6983 & 1.7943 & 20.37269 & 0.16658 & 0.90 & 15.7033 & 14.25569 & 3.9627 \\
\hline 60 & 45 & 8.2063 & 8.1073 & 0.97 & 10.135 & 7.9162 & 3.998 & 25.21692 & 0.18684 & 0.85 & 31.79 & 15.0833 & 5.6382 \\
\hline 60 & 55 & 4.0344 & 4.0234 & 0.99 & 3.1039 & 3.8266 & 1.7720 & 23.76347 & 0.23316 & 0.94 & 18.20551 & 11.78207 & 4.2667 \\
\hline
\end{tabular}

Table 2: Various regression coefficient and statistical parameters of Magee and Peleg model for water loss.

\begin{tabular}{|c|c|c|c|c|c|c|c|}
\hline Conc $\left({ }^{\circ} \mathrm{Bx}\right)$ & Temp. $\left({ }^{\circ} \mathrm{C}\right)$ & $\mathbf{W L} \infty$ & $\beta_{1}$ & $\mathbf{R}^{2}$ & $\chi^{2}$ & $E \%$ & RMSE \\
\hline 40 & 35 & 37.547 & 0.0114 & 0.99 & 3.0124 & 6.6984 & 0.3042 \\
\hline 40 & 45 & 46.569 & 0.0135 & 0.98 & 3.2567 & 10.254 & 0.38547 \\
\hline 40 & 55 & 57.142 & 0.0175 & 0.98 & 4.123 & 8.564 & 0.4587 \\
\hline 50 & 35 & 40.231 & 0.0186 & 0.99 & 11.256 & 7.987 & 1.2354 \\
\hline 50 & 45 & 49.786 & 0.0935 & 0.99 & 17.564 & 10.564 & 0.3154 \\
\hline 50 & 55 & 59.324 & 0.0212 & 0.99 & 3.654 & 11.256 & 0.9574 \\
\hline 60 & 35 & 42.214 & 0.0223 & 098 & 19.564 & 13.564 & 0.5604 \\
\hline 60 & 45 & 52.321 & 0.0243 & 0.99 & 13.254 & 6.354 & 1.2635 \\
\hline 60 & 55 & 60.245 & 0.0258 & 0.99 & 26.145 & 8.954 & 1.321 \\
\hline
\end{tabular}

Table 3: Various regression coefficient and statistical parameters of Auara model for water loss.

and in turn the driving force for osmotic dehydration process [9] and increase in temperature decreases the viscosity of the osmotic solution, decreases the external resistance to mass transfer rate at product suface; and thus facilitate the outflow of water from cubes.

The comparative validity of the various models fitted to the water loss data can also be represented from the predicted curves of various models (Figure 1). The Figure indicates that the predicted values obtained from Magee model are very close to the experimental values.

\section{Empirical Models for Solute Gain during Osmotic Dehydration}

The solute gain during the process of osmotic dehydration at various concentrations and at various temperatures was observed at regular intervals of time. The penetration of solute goes on increasing with the passage of time and become almost constant at the end of process. There was a very good adequacy between predicted and observed data with correlation coefficient ' $\mathrm{R}^{2}$ ' higher than 0.96 for solute gain (Tables 4 and 5) in case of Azuara model. The values for E\%, RMSE and $\chi^{2}$ are less as compared to other models and value of $\mathrm{R}^{2}$ is high than other models, which is the criteria used for the adequacy of good fitting of Model. Adequacy of fitting of Azuara model is in good agreement with the results found by Mundada et al., [27] in case of osmotic dehydration of pomegranate arils.

The comparison of experimental and predicted values of various osmotic dehydration models for solute gain could be analyzed visually in the Figure 2. The predicted values of solute gain given by Azuara model were very close to the experimental values for solute gain during osmotic dehydration of EFY cubes.

According to Azuara model (Table 5), predicted values of equilibrium solute gain were $9.26,9.64,12.86 \mathrm{~g} / 100 \mathrm{~g}$ of fresh sample at

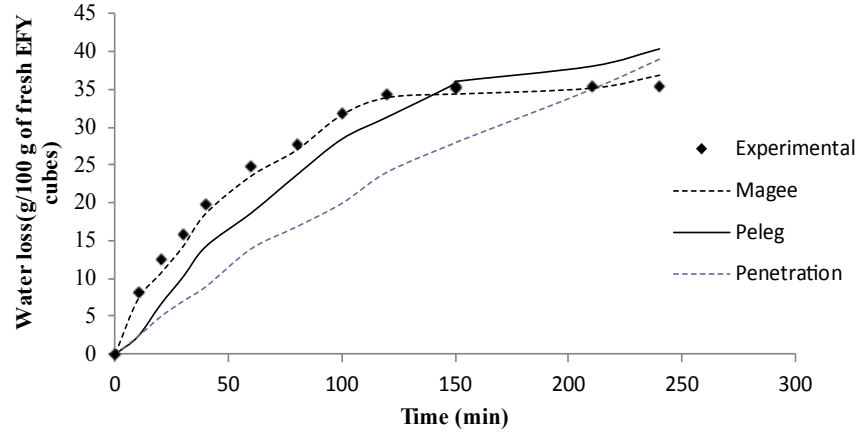

Figure 1: Plot for various predicted and experimental values for water loss with time at $40^{\circ} \mathrm{Bx}$ at $45^{\circ} \mathrm{C}$.

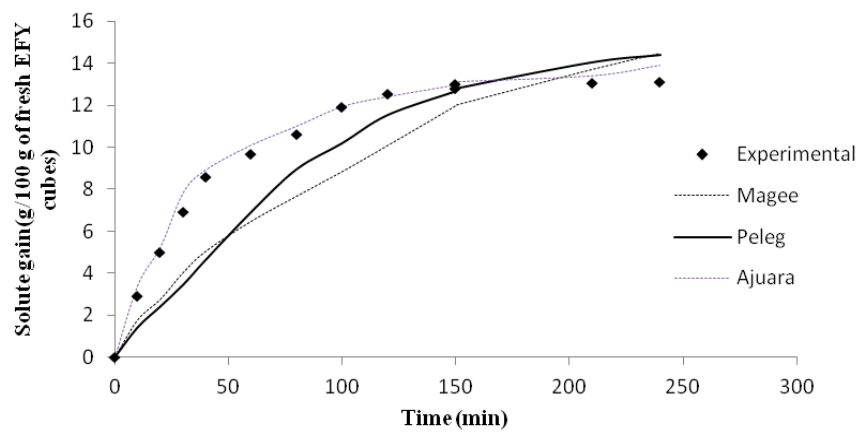

Figure 2: Plot for various predicted and experimental values for solute gain with time at $40^{\circ} \mathrm{Bx}$ at $45^{\circ} \mathrm{C}$. 
Citation: Sangeeta, Hathan BS (2015) Elephant Foot Yam (Amorphophallus paeoniifolius): Osmotic Dehydration and Modelling. J Food Process Technol 6: 499. doi:10.4172/2157-7110.1000499

Page 4 of 5

\begin{tabular}{|c|c|c|c|c|c|c|c|c|c|c|c|c|c|}
\hline \multirow[b]{2}{*}{ Conc. $\left({ }^{\circ} \mathrm{Bx}\right)$} & \multirow[b]{2}{*}{ Temp. $\left({ }^{\circ} \mathrm{C}\right)$} & \multicolumn{6}{|c|}{ Magee model (solute gain) } & \multicolumn{6}{|c|}{ Peleg model (solute gain) } \\
\hline & & A & K & $\mathbf{R}^{2}$ & $\chi^{2}$ & $E \%$ & RMSE & $K_{1}$ & $\mathrm{~K}_{2}$ & $\mathbf{R}^{2}$ & $\chi^{2}$ & $\mathrm{E} \%$ & RMSE \\
\hline 40 & 35 & 1.6957 & 0.7824 & 0.98 & 0.2127 & 4.4275 & 0.3457 & 4.4329 & 0.03458 & 0.91 & 0.573 & 10.69 & 0.7573 \\
\hline 40 & 45 & 2.9609 & 0.8472 & 0.99 & 0.0694 & 2.1855 & 0.2634 & 6.30406 & 0.04279 & 0.94 & 0.592 & 8.442 & 0.7695 \\
\hline 40 & 55 & 3.5877 & 0.9240 & 0.99 & 0.1015 & 1.8886 & 0.3187 & 7.2927 & 0.04805 & 0.97 & 0.309 & 5.342 & 0.5559 \\
\hline 50 & 35 & 2.2932 & 0.7861 & 0.98 & 0.1084 & 3.5912 & 0.3293 & 5.54218 & 0.04001 & 0.93 & 0.641 & 9.9769 & 0.8011 \\
\hline 50 & 45 & 4.0481 & 0.8481 & 0.99 & 0.0529 & 1.9356 & 0.2400 & 7.46864 & 0.04399 & 0.97 & 0.282 & 5.4214 & 0.5312 \\
\hline 50 & 55 & 4.5820 & 1.1402 & 0.99 & 0.1279 & 1.8948 & 0.3576 & 9.1689 & 0.05931 & 0.97 & 0.449 & 4.369 & 0.6707 \\
\hline 60 & 35 & 2.6721 & 0.8614 & 0.99 & 0.0407 & 1.6916 & 0.2018 & 6.20413 & 0.04439 & 0.96 & 0.408 & 6.3006 & 0.6392 \\
\hline 60 & 45 & 4.0604 & 1.0879 & 0.99 & 0.0562 & 1.7448 & 0.2573 & 8.4532 & 0.056201 & 0.96 & 0.586 & 5.5548 & 0.7656 \\
\hline 60 & 55 & 4.6557 & 1.5219 & 0.99 & 0.2668 & 2.6868 & 0.5261 & 10.8119 & 0.07781 & 0.94 & 1.984 & 7.8928 & 1.4088 \\
\hline
\end{tabular}

Table 4: Various regression coefficient and statistical parameters of Magee and Peleg model for solute gain.

\begin{tabular}{|c|c|c|c|c|c|c|c|}
\hline Conc $\left({ }^{\circ} \mathrm{Bx}\right)$ & Temp (C) & $S G_{\infty}$ & $\beta_{2}$ & $\mathbf{R}^{2}$ & $\chi^{2}$ & $E \%$ & RMSE \\
\hline 40 & 35 & 7.521 & 0.0348 & 0.98 & 0.0999 & 5.1326 & 0.0356 \\
\hline 40 & 45 & 8.654 & 0.0254 & 0.99 & 0.0450 & 6.5478 & 0.0645 \\
\hline 40 & 55 & 9.123 & 0.0088 & 0.98 & 0.0654 & 8.654 & 0.0795 \\
\hline 50 & 35 & 9.2654 & 0.0045 & 0.99 & 0.0147 & 9.6479 & 0.0214 \\
\hline 50 & 45 & 9.641 & 0.00145 & 0.99 & 0.1254 & 11.3255 & 0.0145 \\
\hline 50 & 55 & 12.864 & 0.0013 & 0.99 & 0.3159 & 8.987 & 0.0478 \\
\hline 60 & 35 & 10.764 & 0.0064 & 0.98 & 0.2647 & 4.679 & 0.0347 \\
\hline 60 & 45 & 11.965 & 0.00564 & 0.99 & 0.1345 & 11.255 & 0.0614 \\
\hline 60 & 55 & 12.954 & 0.00154 & 0.99 & 0.2359 & 8.789 & 0.0874 \\
\hline
\end{tabular}

Table 5: Various regression coefficient and statistical parameters of Auara model for solute gain.

$35,45,55^{\circ} \mathrm{C}$, respectively, for osmotic solution of $50^{\circ} \mathrm{Bx}$ concentration. Therefore, with increase of temperature of osmotic solution, the values of solute gain at equilibrium have been increased. The values of equilibrium solute gain were $9.12,12.86,12.954 \mathrm{~g} / 100 \mathrm{~g}$ of fresh sample in $40,50,60^{\circ} \mathrm{Bx}$, respectively, at $55^{\circ} \mathrm{C}$ of osmotic solution temperature as predicted by Azuara model. Therefore, with increase of concentration of osmotic solution, the values of solute gain at equilibrium have been increased. The values of $\beta_{2}$ indicates that the rates of water loss were higher at higher concentrations and temperature in comprasion to the low values of concentration and temperature. It may be due to the fact that the low concentration of sugar syrup may get diluted and reach the near saturation point quickly. An increase in osmotic solution concentration increases the concentration gradient and in turn the driving force for osmotic dehydration process and high temperature decrease the resistance due to high viscosity by lowering down the viscosity of highly concentrated solution.

\section{Conclusion}

The osmotic solution concentration, temperature and time have significant effect on water loss and solute gain during osmotic dehydration of EFY cubes. The effect of process variables on water loss and solute gain can be represented by the model constants. Among different applied equations, Magee and Auara model showed the best fitting to the experimental data for water loss and solid gain, respectively. Therefore, the osmotic dehydration process of EFY cubes can be successfully represented by appropriate models for scale up purposes.

\section{References}

1. Ravi V, Ravindran CS, Suja G (2009) Growth and Productivity of Elephant Foo Yam (Amorphophallus paeoniifolius (Dennst. Nicolson): an Overview. J Root Crops 35: 131-142.

2. Mishra RS, Nedunchezhiyan M, Swam TMS, Edison S (2002) Mass multiplication technique for producing quality planting material of Amorphophallus paeoniifolius. Trop Sci 34: 371-376.

3. Bradbury JH, Holloway WD (1988) Chemistry of Topical Root Crops: Significance for National and Agriculture in the Pacific. Australian Centre for International Agriculture Research 51-99.

4. Sreerag RS, Jayaprakas CA, Sajeev MS (2014) Physico-Chemical and Textural Changes in Elephant Foot Yam (Amorphophallus paeoniifolius) Tubers Infested by the Mealy Bug Rhizoecus Amorphophalli Betrem during Storage. J Post harvest Technol 02: 177-187.

5. García-Martínez E, Martínez-Monzo J, Camacho MM, Martínez-Navarrete N (2002) Osmotic Solution as Ingredient in New Product Formulation. Food Res Int 35: 307-312.

6. Corzo O, Bracho N (2005) Osmotic dehydration kinetics of sardine sheets using Zugarramurdi and Lupín model. J Food Eng 66: 51-56.

7. Rahman MS, Lamb J (1990) Osmotic dehydration of pineapple. J Food Sci Technol 27: 150-152.

8. Madamba PS (2003) Thin layer drying models for osmotically predried young coconut. Drying Technol 21: 1759-1780.

9. Rastogi NK, Raghavarao KSMS (2004) Mass transfer during osmotic dehydration of pineapple: Considering Fickian diffusion in cubical configuration. LWT Food Sci Technol 37: 43-47.

10. Rastogi NK, Raghavarao KSMS, Niranjan K, Knorr D (2002) Recent developments in osmotic dehydration: methods to enhance mass transfer. Trends Food Sci Technol 13: 58-69.

11. Panades G, Castro D, Chiralt A, Fito P Nunez M, et al (2008) Mass transfer mechanisms occurring in osmotic dehydration of guava. J Food Eng 87: 386-390

12. Peleg $M$ (1988) An empirical model for the description of moisture sorption curves. J Food Sci 53: 1216-1219.

13. Azuara E, Beristain Cl, Garcia HS (1992) Development of a mathematical model to predict kinetics of osmotic dehydration. J Food Sci Technol 29: 239 242

14. Magee TRA, Murphy WR, Hassaballah AA (1983) Internal mass transfer during osmotic dehydration of apple slices in sugar solution. Irish J Food Sci Technol 7: $147-155$. 
Citation: Sangeeta, Hathan BS (2015) Elephant Foot Yam (Amorphophallus paeoniifolius): Osmotic Dehydration and Modelling. J Food Process Technol 6: 499. doi:10.4172/2157-7110.1000499

15. Rahman MS (1992) Osmotic dehydration kinetics of food. Indian Food Ind 15: 20-24

16. Kaymak-Ertekin F, Sultanoglu M (2001) Moisture sorption isotherm characteristics of peppers. J Food Eng 47: 225-231.

17. García-Pascual P, Sanjuan N, Melis R, Mulet A (2006) Morchella esculenta (morel) rehydration process modelling. J Food Eng 72: 346-353.

18. Singh B, KumarA, Gupta AK (2007) Study of mass transfer kinetics and effective diffusivity during osmotic dehydration of carrot cubes. J Food Eng 79: 471-480.

19. Khin MM, Zhou W, Perera CO (2006) A study of the mass transfer in osmotic dehydration of coated potato cubes. J Food Eng 77: 84-95.

20. Schmidt FC, Carciofi BAM, Laurindo JB (2009) Application of diffusive and empirical models to hydration dehydration and salt gain during osmotic treatment of chicken breast cuts. J Food Eng 91: 553-559.

21. Mercali GD, Marczak LDF, Tessaro IC, Norena CPZ (2010) Evaluation of water, sucrose and $\mathrm{NaCl}$ effective diffusivities during osmotic dehydration of banana (Musa sapientum, shum.). LWT - Food Sci Technol 2: 123-128.
22. Manivannan P, Rajasimman M (2008) Osmotic Dehydration of Beetroot in Salt Solution: Optimization of Parameters through Statistical Experimental Design. Int J Chem Biol Eng 1: 4

23. Chopra CS (2001) Osmo-vacuum drying of carrots: Effect of salted syrup on drying behaviour and product quality. Beverage and Food World 15-17.

24. Singh S, Shivhare US, Ahmed J, Raghavan (1999) Osmotic concentration kinetics and quality of carrot preserve. Food Res Int 32: 509-514.

25. Azoubel PM, Murr FEX (2004) Mass transfer kinetics of osmotic dehydration of cherry tomato. J Food Eng 61: 291-295.

26. Azarpazhooh E, Ramaswamy HS (2010) Evaluation of diffusion and Azuara models for mass transfer kinetics during microwave-osmotic dehydration of apples under continuous flow medium-spray conditions. Drying Technol 28 : 57-67.

27. Mundada M, Hathan BS, Maske S (2011) Mass transfer kinetics during osmotic dehydration of pomegranate arils. J Food Sci 76: 31-39. 